\title{
Influence of Cultural and Pest Management Practices on Performance of Runner, Spanish, and Virginia Market Types in North Carolina
}

\author{
Bridget R. Lassiter, ${ }^{1}$ David L. Jordan, ${ }^{2}$ Gail G. Wilkerson, ${ }^{2}$ \\ Barbara B. Shew, ${ }^{3}$ and Rick L. Brandenburg ${ }^{4}$ \\ ${ }^{1}$ North Carolina Department of Agriculture and Consumer Services, 1060 Mail Service Center, Raleigh, NC 27699-1060, USA \\ ${ }^{2}$ Department of Crop Science, North Carolina State University, P.O. Box 7620, Raleigh, NC 27695-7620, USA \\ ${ }^{3}$ Department of Plant Pathology, North Carolina State University, P.O. Box 7903, Raleigh, NC 27695, USA \\ ${ }^{4}$ Department of Entomology, North Carolina State University, P.O. Box 7613, Raleigh, NC 27695, USA \\ Correspondence should be addressed to David L. Jordan; david_jordan@ncsu.edu
}

Received 14 February 2016; Accepted 8 March 2016

Academic Editor: Tibor Janda

Copyright ( 2016 Bridget R. Lassiter et al. This is an open access article distributed under the Creative Commons Attribution License, which permits unrestricted use, distribution, and reproduction in any medium, provided the original work is properly cited.

\begin{abstract}
Virginia market type peanut (Arachis hypogaea L.) cultivars are grown primarily in North Carolina, South Carolina, and Virginia in the US, although growers in these states often plant other market types if marketing opportunities are available. Information on yield potential and management strategies comparing these market types is limited in North Carolina. In separate experiments, research was conducted to determine response of runner, Spanish, and Virginia market types to calcium sulfate and inoculation with Bradyrhizobium at planting, planting and digging dates, planting patterns, and seeding rates. In other experiments, control of thrips (Frankliniella spp.) using aldicarb, southern corn rootworm (Diabrotica undecimpunctata Howardi) using chlorpyrifos, eclipta (Eclipta prostrata L.) using threshold-based postemergence herbicides, and leaf spot disease (caused by the fungi Cercospora arachidicola and Cercosporidium personatum) fungicide programs was compared in these market types. Results showed that management practice and market types interacted for peanut pod yield in only the planting date experiment. Yield of runner and Virginia market types was similar and exceeded yield of the Spanish market type in most experiments.
\end{abstract}

\section{Introduction}

Virginia market type peanut cultivars compose the majority of peanut (Arachis hypogaea L.) production in North Carolina [1]. Occasionally, production of runner and Spanish market types is considered in North Carolina depending on marketing opportunities. Runner and Virginia market types are both described as Virginia botanicals and have similar morphological features including branching patterns $[2,3]$. Differences between these market types are associated with selection through breeding programs that have differentiated kernel size as a result of market demand. In contrast, Spanish market types differ botanically from runner and Virginia market types and express different morphological features $[3,4]$. Spanish market types are upright with limited pod set external to the crown of the plant which is in contrast to runner and Virginia market types that set pods close to the crown of the plant and on lateral branches. These differences impact yield potential and most likely can impact reaction to pests.

Yield of runner and Virginia market type peanut is often similar when production of both market types is optimized $[2,5,6]$. However, pest management and cultural practices required to optimize yield of these market types can differ $[2,4,7]$. For example, seeding rate in $\mathrm{kg} / \mathrm{ha}$ due to seed size needed to obtain optimum stands and calcium requirement for kernel development are often lower for runner market types compared with Virginia market types $[2,8]$. Cultivars with smaller kernel size have a lower calcium requirement and in many cases do not require supplemental 
calcium $[7,9,10]$. Consequently, production costs for Virginia market types often exceed that of runner market types [2, 5].

Planting and digging date can impact yield and market grade characteristics of peanut $[4,11]$. Optimum planting dates generally differ on a regional basis [12]. Spanish market types have historically been grown in the southwestern US, and data reflecting peanut response to planting and digging dates compared with runner and Virginia market types in North Carolina are limited. Spanish market types also reach optimum maturity in fewer days than runner or Virginia market types and this can lead to reduced costs associated with disease management $[4,13]$. However, yield potential of Spanish market types is often lower than yield potential of both runner and Virginia market types [14]. This reduced yield potential is often attributed to the limited production of pods on lateral branches compared with Virginia and runner market type cultivars. Also, inherent dormancy is greater in Virginia and runner market types than Spanish market types $[15,16]$. This creates concern over seed quality of Spanish market types when grown in North Carolina given that excessive rainfall through tropical weather events can occur after peanut reach optimum maturity but before digging and harvesting. These wet field conditions can delay or otherwise interfere with digging and harvest operations, resulting in the possibility of Spanish market type seeds germinating in the field. The balance between lower yield of Spanish market types and lower costs of production compared with runner and Virginia market types has not been compared in North Carolina.

Injury from thrips $[17,18]$ and southern corn rootworm [19] can reduce peanut yield. Likewise, interference from weeds with peanut can lower yields and can reduce efficiency of digging pods and inverting vines [20].

More agronomic information relative to the production of runner, Spanish, and Virginia market types would be valuable in helping North Carolina growers develop comprehensive management strategies for these market types when economic opportunities become available. Therefore, research was conducted in North Carolina to determine response of these market types to planting date, digging date, inoculation with Bradyrhizobium, application of supplemental calcium, and control of leaf spot and stem rot diseases, thrips, corn rootworm, and weeds.

\section{Materials and Methods}

2.1. General Methods for All Experiments. Experiments were conducted at the Peanut Belt Research Station located near Lewiston-Woodville $(36.07 \mathrm{~N},-77.11 \mathrm{~W})$ on a mix of Norfolk loamy sand (fine-loamy, kaolinitic, thermic typic Kandiudults) and Goldsboro loamy sand (fine-loamy, siliceous, thermic Aquic Paleudults) from 2005 to 2008 in conventionally prepared raised seed beds. Plot size was 2 rows wide $(91 \mathrm{~cm})$ by $11 \mathrm{~m}$ long. Experiments were conducted specifically to compare response of the Virginia market type cultivar Gregory [21], the runner market type cultivar Georgia Green [22], and the Spanish market type cultivar
Tamspan 90 [23] when exposed to various production and pest management practices. With the exception of the experiment comparing response to single and twin row planting patterns, in-row seeding rate of these respective cultivars was 17,20 , and 27 seeds/m as recommended in regions of the US where these cultivars are most popular $[6,12,24]$. With the exception of the planting date experiment, all cultivars were planted between May 2 and May 10. Peanut in all experiments was irrigated periodically in July and August to supplement rainfall to maintain growth and development. The combination of rain and irrigation for each week during this time period was approximately $2 \mathrm{~cm}$. Two years of corn (Zea mays L.) separated peanut plantings.

Aldicarb (Temik Insecticide, Bayer Crop Science, Research Triangle Park, NC) was applied at $1.1 \mathrm{~kg}$ ai $/ \mathrm{ha}$ in the seed furrow at planting before seed drop and prior to slit closure in all experiments except in the experiment where thrips response to market types was compared. Chlorpyrifos (Lorsban 15G Insecticide, Dow AgroSciences, Indianapolis, IN) was applied at $2.4 \mathrm{~kg}$ ai/ha in a $30 \mathrm{~cm}$ band over the row at the R2 [25] stage of growth approximately 40 days after planting to control southern corn rootworm except in the experiment designed to determine market type response to this insect.

$S$-metolachlor (Dual II Magnum Herbicide, Syngenta Crop Protection, Greensboro, NC) was applied at $0.91 \mathrm{~kg} a \mathrm{i} / \mathrm{ha}$ over the entire test area in all experiments. With the exception of the weed management experiment, postemergence herbicides including acifluorfen (Ultra Blazer Herbicide, BASF Corporation, Research Triangle Park, NC) at $0.42 \mathrm{~kg}$ ai $/$ ha plus bentazon (Basagran Herbicide, BASF Corporation, Research Triangle Park, NC) at $1.7 \mathrm{~kg}$ ai $/$ ha plus 2,4-DB (Butyrac 200 Herbicide, Albaugh Inc., Ankeny, IA) at $0.28 \mathrm{~kg}$ ai/ha were applied to control escaped broadleaf weeds and sedges when weeds were 2 to $8 \mathrm{~cm}$ in height. Clethodim (Select 2EC Herbicide, Valent USA Corp., Walnut Creek, CA) at $0.14 \mathrm{~kg}$ ai $/$ ha was applied to control escaped annual grasses. Appropriate adjuvants were included with postemergence herbicides.

In all experiments except the disease management experiment, fungicides consisted of chlorothalonil (Bravo Weather Stik Fungicide, Syngenta Crop Protection, Greensboro, NC) applied at the R1 growth stage [25] at $1.23 \mathrm{~kg}$ ai $/ \mathrm{ha}$ followed by two applications of pyraclostrobin (Headline Fungicide, BASF Corporation, Research Triangle Park, NC) at $0.17 \mathrm{~kg}$ ai $/$ ha spaced two weeks apart in mid July and early August. Tebuconazole (Folicur Fungicide, Bayer Crop Science, Research Triangle Park, NC) was applied at $0.21 \mathrm{~kg}$ ai $/$ ha in mid August followed by a final application of chlorothalonil at $0.50 \mathrm{~kg}$ ai $/$ ha in early September (runner and Virginia market types only).

Pod yield was determined in all experiments by harvesting 4-7 days after digging and vine inversion. Final yield was adjusted to $8 \%$ moisture. With the exception of the experiment evaluating the interaction of market types with digging dates, each market type was dug at optimum maturity based on pod mesocarp color as described by Williams and Drexler [26]. 
2.2. Methods Specific to Each Experiment. Peanut response to planting date was compared using planting dates of approximately May 2, May 20, and June 5 during 2005-2008. The impact of digging date on yield of market types was compared by planting peanut in early May and digging approximately September 10, September 25, and October 10 irrespective of pod maturity.

Peanut response to calcium sulfate applied at the R1 growth stage [25] in the form of USG Ben Franklin Landplaster applied at $900 \mathrm{~kg} / \mathrm{ha}$ in a band of $45 \mathrm{~cm}$ in $91 \mathrm{~cm}$ row. This formulation contains $85 \%$ calcium sulfate. Benefits of applying inoculant to promote biological nitrogen fixation were determined by comparing peanut treated with Bradyrhizobium inoculant (Optimize Lift, formally Nitragin Co. and currently Monsanto BioAg., St. Louis, MO) at $445 \mathrm{~mL} / \mathrm{ha}$ applied in the seed furrow at planting as previously described. This formulation of liquid inoculant contains $2.2 \times 10^{9}$ viable cells/g.

Peanut response in single rows as described previously was compared with peanut grown in a twin row planting pattern consisting of peanut rows $20 \mathrm{~cm}$ apart on $91 \mathrm{~cm}$ centers. The seeding rate for each cultivar was increased by $15 \%$ in the twin row pattern to decrease presence of skips in the individual rows. This has been a traditional practice by growers in North Carolina when planting in twin row patters. Therefore, the comparison was a combination of both planting pattern and increased seeding rate.

Management of thrips, southern corn rootworm, eclipta, and foliar diseases was determined in separate experiments. Peanut market type response to thrips injury was compared by applying no insecticide or aldicarb in the seed furrow as described previously. Injury caused by thrips feeding was recorded 3 weeks after planting by determining the percentage of recently emerged randomly selected leaflets exhibiting thrips feeding injury out of 10 leaflets examined. Peanut pod injury caused by southern corn rootworm was determined by comparing to peanut not treated with chlorpyrifos as described previously. One hundred pods were collected from each plot in the field within 2 weeks prior to digging and gently washed to remove soil to determine the percent scarred by southern corn rootworm.

Response to weed management was determined by comparing results using the threshold-based program Herbicide Application Decision Support System (HADSS) [27] to determine the most economical weed control program to results using a standard program. Weed species distribution and number of each species were determined 3 weeks after planting from two rows by $5.5 \mathrm{~m}$ in length within 2 days before herbicide application. These data were used to determine the most economical postemergence herbicide to apply using HADSS, which for both years was paraquat (Gramoxone Inteon Herbicide, Syngenta Crop Protection, Greensboro, NC) at $0.14 \mathrm{~kg}$ ai/ha plus bentazon (BASF Corp., Research Triangle Park, NC) at $0.28 \mathrm{~kg} / \mathrm{ha}$. The standard herbicide program was imazapic (Cadre Herbicide, BASF Corp., Research Triangle Park, NC) at $0.07 \mathrm{~kg}$ ai $/$ ha. Visual estimates of percent eclipta control were recorded in early August on a scale of 0 to 100 where $0=$ no control and $100=$ complete control. Foliar chlorosis, necrosis, plant stunting, and plant density were considered when making the visual estimate.

Peanut canopy defoliation caused by early and late leaf spot was determined for three fungicide programs including (1) no fungicide, (2) two sprays initiated at the R1 growth stage [25] and spaced apart by two weeks, and (3) four or five sprays initiated at pegging followed by biweekly sprays of fungicide through September. Fungicides for the program containing only two sprays were chlorothalonil followed by pyraclostrobin at rates described previously. The fungicide program with four sprays included chlorothalonil followed by two applications of pyraclostrobin and one application of tebuconazole at the rates described previously for all market types. A final application of chlorothalonil at the rate described previously was applied for runner and Virginia market types. Only 4 applications were used in regime 3 for the Spanish market type because this cultivar reached optimum maturity and was harvested prior to application of the final spray. Visible estimates of canopy defoliation on a scale of 0 to $100 \%$ were determined immediately prior to digging where $0=$ no defoliation and $100=$ the entire canopy defoliated. While the Florida scale [28] is often used as a subjective scale for comparing efficacy of fungicides in peanut, in these experiments only defoliation values were used. Canopy defoliation would be more readily adopted by practitioners and growers.

2.3. Experimental Design and Statistical Analyses. With the exception of the experiment with planting dates, the design was a split plot with market types serving as the whole plot unit and cultural or pest management practices serving as subplot units. In the planting date experiment, planting dates served as whole plot units while market types served as subplot units. The decision to define whole plot units was based on logistics for planting date, ease of determining differences in maturity of market types, and ability to dig and invert vines. Combinations of whole plot and subplots units were replicated 4 times in all experiments.

Data for pod yield and measurements associated with pest management were subjected to analysis of variance appropriate for the treatment structure. Years of each experiment and replications were considered random effects while market types and cultural and pest management practices were considered fixed effects. Means for significant main effects and interactions were separated using Fisher's Protected LSD Test at $p \leq 0.05$ using the general linear model procedure of SAS V $9.1[29]$.

\section{Results and Discussion}

The major objective of this research was to determine if market type cultivars interacted with management practices. The interaction of market type $\times$ management practice was significant for pod yield in only 1 of 9 experiments (Tables 1 and 2). The interaction of year $\times$ market type $\times$ management practice was not significant for pod yield in any experiment (Tables 1 and 2). In contrast, the main effect of market type was significant in all experiments for pod yield with the 
TABLE 1: Analysis of variance $(p>F)$ for interactions of year, peanut market type, and management practices including planting date, digging date, inoculation with Bradyrhizobium, and planting pattern.

\begin{tabular}{|c|c|c|c|c|c|}
\hline \multirow{2}{*}{ Source of variation } & \multicolumn{5}{|c|}{ Management practice } \\
\hline & Planting date & Digging date & Gypsum & Inoculant & Planting pattern \\
\hline Year & $<0.0001$ & $<0.0001$ & $<0.0001$ & $<0.0001$ & $<0.0001$ \\
\hline Market type & $<0.0001$ & $<0.0001$ & $<0.0001$ & $<0.0001$ & 0.0014 \\
\hline Year $\times$ market type & 0.1525 & 0.0002 & 0.0016 & 0.0028 & 0.4098 \\
\hline Management practice & 0.0896 & $<0.0001$ & 0.4393 & 0.5461 & 0.3713 \\
\hline Market type $\times$ management & 0.0433 & 0.3470 & 0.5037 & 0.9687 & 0.3884 \\
\hline Year $\times$ management & 0.7274 & 0.0292 & 0.3513 & 0.8215 & 0.5709 \\
\hline Year $\times$ market type $\times$ management & 0.9769 & 0.7286 & 0.5795 & 0.6912 & 0.1976 \\
\hline Coefficient of variation (\%) & 13.7 & 12.9 & 14.2 & 10.7 & 12.9 \\
\hline Number of trials & 3 & 5 & 4 & 3 & 4 \\
\hline
\end{tabular}

interaction of year $\times$ market type significant for pod yield in 6 of 9 experiments (Tables 1 and 2). Rather than present means for the year $\times$ market type interaction for all experiments, a summary table was prepared to compare the percentage of times a difference in yield of market types was observed with respect to the total number of trials (year and experiment combination) (Table 3).

Pod yield was similar for all market types in $23.4 \%$ of the 47 trials (Table 4). In $61.7 \%$ of trials yield of both the runner and Virginia market types exceeded that of the Spanish market type. In $68.1 \%$ of comparisons yield of runner and Virginia market types was similar while in $17.1 \%$ of comparisons yield of the Virginia market type exceeded yield of the runner market type. Yield of the runner market type exceeded that of the Virginia market types in $10.6 \%$ of the trials. Although variation in yield has been reported [22, 3035], our results indicate that Virginia and runner market types generally yield more than Spanish market types. In order for growers to incorporate Spanish market types into their operations, pricing incentives will need to be considered for Spanish market types. Savings in production costs are often noted for Spanish market types when compared with both runner and Virginia market types due to seed costs, fertilizer inputs, and disease management programs $[12,24]$.

The interaction of planting date $\times$ market type was significant for pod yield (Table 1). When comparing within planting dates, yield of the Virginia market type exceeded that of the runner and Spanish market types when planted on May 2 (Table 4). When planted on May 24, yield of the Virginia market type was higher than yield of the Spanish market type; yield of the runner market type was intermediate. Yield of the runner market type was higher than yield of the Spanish market type when planted on June 5 while yield of the Virginia market type was intermediate between these market types. Although yield can be variable, yield is generally higher on a more consistent basis when Virginia market type cultivars are planted in early or late May compared with planting in early June $[11,36]$. Less information relative to runner and Spanish market type response to planting date is available for North Carolina and surrounding states.

The interaction of year $\times$ digging date was significant for pod yield (Table 1 ). When pooled over market types, delaying digging from September 10 to September 25 or September 25 to October 15 increased yield during 2005 and 2006 (Table 5). In 2007, delaying digging from September to September 25 or October 15 increased yield; there was no difference between September 25 and October 15 planting dates. Lack of a significant interaction of market type $\times$ digging date was not expected because Virginia and runner market type cultivars often reach optimum maturity later than Spanish market types $[12,24]$. In the other experiments in this study the Spanish market type cultivar was dug $10 \mathrm{~d}$ earlier than the Virginia and runner market types based on pod mesocarp color. It is possible that allowing the Spanish market type to remain in the field longer may have resulted in higher yields for this market type. Additional research is needed to more clearly define the interaction of digging date and market type with respect to pod yield.

Regardless of market type, no difference in yield was observed when calcium sulfate was applied or when Bradyrhizobium inoculant was applied in the seed furrow at planting (Tables 1 and 6). Native inoculum in soil most likely was adequate for nitrogen fixation in the absence of Bradyrhizobium inoculation at this location. The rotation sequence at this location was two years of corn between peanut plantings. In other research in North Carolina [37], peanut yield was $220 \mathrm{~kg} / \mathrm{ha}$ and $1,750 \mathrm{~kg} / \mathrm{ha}$ higher when peanut was planted in short rotations and in fields without a recent history of peanut plantings, respectively. Previous research [38] with the Virginia market type cultivar Gregory showed a positive response to supplemental calcium in some but not all experiments. Lack of response of the runner and Spanish market type to calcium sulfate was not surprising. Soil calcium is often adequate for these small-seeded cultivars [12]. Soil calcium was not determined in this experiment; however, these fields are fertilized annually and lime is applied routinely to maintain soil $\mathrm{pH}$ at 6.0 or higher. Soil calcium is a relatively poor indicator of peanut response to supplemental calcium of Virginia market types [10].

Peanut yield was similar for single and twin row planting patterns regardless of market type (Tables 1 and 6). Although a yield increase in twin rows often occurs when tomato spotted wilt (caused by a Tospovirus) of peanut is present [39], incidence of tomato spotted wilt of peanut was low at this 


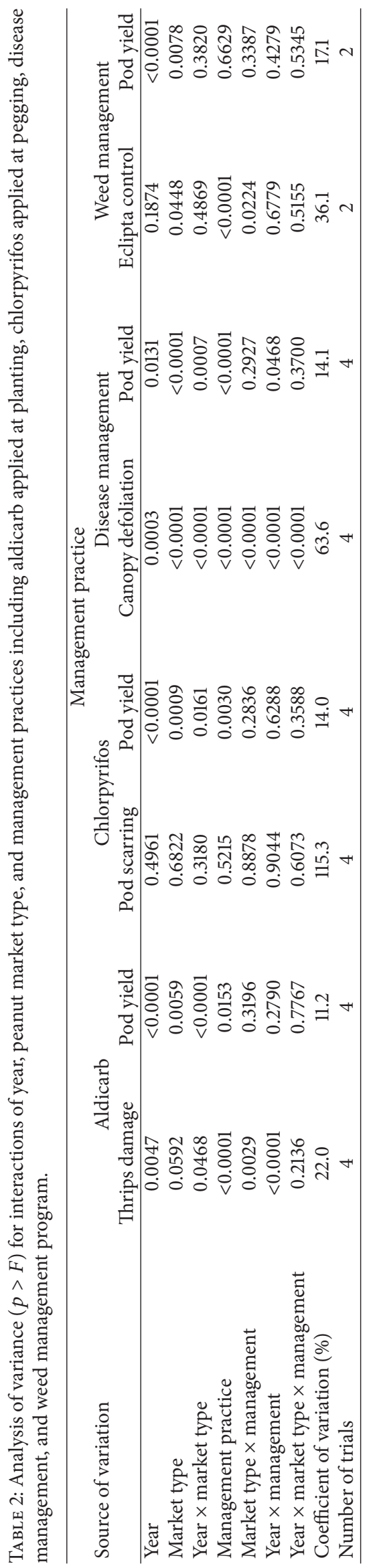


TABLE 3: Number and percentage of 47 trials comparing differences in yield of runner, Virginia, and Spanish market types using year and management practice combinations as a trial.

\begin{tabular}{lcc}
\hline Category & Number of trials & Percentage of trials \\
\hline Yield equal for all market types & 11 & 23.4 \\
Yield of both runner and Virginia market types exceeding yield of Spanish market type & 29 & 61.7 \\
Yield of Spanish market type exceeding yield of both runner and Virginia market types & 32 & 2.1 \\
Yield of runner and Virginia market types equal & 8 & 58.1 \\
Yield of Virginia market type exceeding yield of runner market type & 5 & 17.1 \\
Yield of runner market type exceeding yield of Virginia market type & 2 & 10.6 \\
Yield of Spanish market type exceeding yield of runner market type & 1 & 4.3 \\
Yield of Spanish market type exceeding yield of Virginia market type & 47 & 2.1 \\
Total & & - \\
\hline
\end{tabular}

TABLE 4: Influence of planting date on yield of runner, Virginia, and Spanish market types ${ }^{\mathrm{a}}$.

\begin{tabular}{lccc}
\hline Planting date & Runner & $\begin{array}{c}\text { Market type } \\
\text { Virginia } \\
\mathrm{kg} / \mathrm{ha}\end{array}$ & Spanish \\
\hline May 2 & $4,390 \mathrm{~b} \mathrm{~A}$ & $5,110 \mathrm{a} \mathrm{A}$ & $3,930 \mathrm{~b} \mathrm{~B}$ \\
May 24 & $4,870 \mathrm{ab} \mathrm{A}$ & $5,190 \mathrm{a} \mathrm{A}$ & $4,480 \mathrm{~b} \mathrm{~A}$ \\
June 5 & $4,840 \mathrm{a} \mathrm{A}$ & $4,450 \mathrm{ab} \mathrm{B}$ & $4,110 \mathrm{~b} \mathrm{AB}$ \\
\hline
\end{tabular}

${ }^{\mathrm{a}}$ Means within a planting date followed by the same lowercased letter are not significantly different according to Fisher's Protected LSD Test at $p \leq 0.05$. Means within the same market type followed by the same uppercased letter are not significantly different according to Fisher's Protected LSD Test at $p \leq$ 0.05. Data are pooled over years.

TABLE 5: Influence of digging date on pod yield for experiments comparing digging dates ${ }^{\mathrm{a}}$.

\begin{tabular}{lccc}
\hline Digging date & 2005 & $\begin{array}{c}2006 \\
\mathrm{~kg} / \mathrm{ha}\end{array}$ & 2007 \\
\hline September 10 & $4,210 \mathrm{c}$ & $4,390 \mathrm{c}$ & $3,520 \mathrm{~b}$ \\
September 25 & $4,560 \mathrm{~b}$ & $4,770 \mathrm{~b}$ & $4,100 \mathrm{a}$ \\
October 15 & $5,070 \mathrm{a}$ & $5,290 \mathrm{a}$ & $4,110 \mathrm{a}$ \\
\hline
\end{tabular}

${ }^{a}$ Means within an experiment with a management practice and followed by the same letter are not significantly different according to Fisher's Protected LSD Test at $p \leq 0.05$. Data are pooled over market types.

location during the years these experiments were conducted. However, in absence of tomato spotted wilt, yield of Virginia market type peanut was higher in twin rows compared with single rows in some but not all experiments [40].

Applying either aldicarb or chlorpyrifos increased yield compared with nontreated peanut irrespective of market type (Tables 2 and 6). Injury from thrips feeding often reduces peanut yield in absence of control strategies in North Carolina $[17,41]$. Response to aldicarb was expected because injury decreased from 8.3 on a scale of 0 to 10 when aldicarb was not applied to 0.9 when aldicarb was applied in the seed furrow at planting (Table 7). When pooled over aldicarb treatments, thrips injury was lower for the Virginia market type (4.2) compared with either the runner market type (4.7) or the Spanish market type (5.2) (Table 7). Although thrips injury for the Spanish market type exceeded that of the runner market type, these differences were not reflected in yield (Tables 2 and 6).

No difference in pod scarring was noted among market types (2.6 to $3.5 \%$, data not shown in tables) although yield differences were noted (Tables 2 and 6). Although not documented in this experiment, higher yield following application of chlorpyrifos could have been attributed to control of other insects or impacts on stem rot (Sclerotium rolfsii Sacc.) [42]. Johnson et al. [18] reported higher yields of Virginia market type peanut when chlorpyrifos was applied even when the amount of pod scarring was relatively low compared with nontreated peanut.

Although differences in eclipta control were noted between the standard herbicide program and the herbicide recommendation based on HADSS when comparing market types, these differences did not translate into a difference in yield (Tables 2 and 6). The interaction of market type $\times$ herbicide program was most likely caused by the differences in magnitude of control between herbicide programs for market types. The residual control provided by imazapic in the standard herbicide program may have contributed to better control. However, both herbicide programs provided adequate weed suppression during the critical weed-free period for peanut [43].

Considerable variation was noted among years and market types for peanut canopy defoliation (Table 8). Regardless of fungicide regime, defoliation did not exceed $18 \%$ for the runner market type when comparing across years. In contrast, defoliation in absence of fungicide for the Virginia market type ranged from 18 to $60 \%$, and 8 to $39 \%$ for the Spanish market type. When a full-season fungicide regime was included defoliation was no more than $4 \%$. When pooled over years for the interaction of fungicide regime $\times$ market type, canopy defoliation was the lowest for all market types when 4-5 fungicide sprays were included compared with the no-fungicide control or 2 early season sprays (Table 9). When fungicide was not applied, the least amount of canopy defoliation was noted for the runner market type with the Virginia market type expressing the greatest degree of canopy defoliation. Defoliation of the Spanish market type was intermediate between the runner and Spanish market type. When 2 fungicide sprays were included, canopy defoliation 
TABLE 6: Influence of peanut market type on pod yield for experiments comparing gypsum, inoculant, planting pattern, aldicarb, and chlorpyrifos treatments.

\begin{tabular}{|c|c|c|c|c|c|c|}
\hline \multirow[b]{2}{*}{ Management input } & \multicolumn{6}{|c|}{ Experiment with the management practice } \\
\hline & Calcium sulfate & Inoculant & $\begin{array}{r}\text { Planting pattern } \\
\mathrm{kg}\end{array}$ & Aldicarb & Chlorpyrifos & Weed scouting \\
\hline No & 4,000 & 4,590 & 4.100 & 3,770 & 3,240 & 3,750 \\
\hline Yes & 3,910 & 4,660 & 4,200 & $4,000^{*}$ & $3,540^{*}$ & 3,670 \\
\hline
\end{tabular}

${ }^{*}$ A significant difference at $p \leq 0.05$. Data are pooled over years and market types.

TABLE 7: Thrips injury and eclipta control as influenced by market type and management practice ${ }^{\mathrm{a}}$.

\begin{tabular}{|c|c|c|c|c|}
\hline \multirow[b]{2}{*}{ Market type } & \multicolumn{2}{|c|}{ Thrips injury 2 weeks after emergence } & \multicolumn{2}{|c|}{ Eclipta control 3 weeks before digging } \\
\hline & No aldicarb & Aldicarb $^{\mathrm{b}}$ & Weed scouting $^{c}$ & Standard program \\
\hline & \multicolumn{2}{|c|}{ Scales 1-10 } & \multicolumn{2}{|c|}{$\%$} \\
\hline Runner & $8.3 \mathrm{~b}$ & $1.0 \mathrm{~d}$ & $55 \mathrm{c}$ & $75 \mathrm{~b}$ \\
\hline Virginia & $7.4 \mathrm{c}$ & $1.0 \mathrm{~d}$ & $53 \mathrm{c}$ & $95 \mathrm{a}$ \\
\hline Spanish & $9.4 \mathrm{a}$ & $0.8 \mathrm{~d}$ & $24 \mathrm{~d}$ & $88 \mathrm{ab}$ \\
\hline
\end{tabular}

${ }^{a}$ Means for thrips injury and eclipta control followed by the same letter are not significantly different according to Fisher's Protected LSD Test at $p \leq 0.05$.

${ }^{\mathrm{b}}$ Aldicarb applied at $1.1 \mathrm{~kg} / \mathrm{ha}$ in the seed furrow at planting.

${ }^{\mathrm{c}}$ Paraquat plus bentazon applied postemergence.

${ }^{\mathrm{d}}$ Imazapic applied postemergence.

TABle 8: Peanut canopy defoliation caused by leaf spot disease as influenced by fungicide program within a market type ${ }^{\mathrm{a}}$.

\begin{tabular}{lccccc}
\hline Market type & $\begin{array}{c}\text { Fungicide } \\
\text { sprays } \\
\text { Number }\end{array}$ & 2005 & 2006 & 2007 & 2008 \\
\hline Runner & 0 & $11 \mathrm{a}$ & $8 \mathrm{a}$ & $18 \mathrm{a}$ & $5 \mathrm{a}$ \\
Runner & 2 & $10 \mathrm{a}$ & $4 \mathrm{a}$ & $5 \mathrm{~b}$ & $0 \mathrm{a}$ \\
Runner & 5 & $0 \mathrm{a}$ & $1 \mathrm{a}$ & $4 \mathrm{~b}$ & $0 \mathrm{a}$ \\
\hline Virginia & 0 & $60 \mathrm{a}$ & $24 \mathrm{a}$ & $47 \mathrm{a}$ & $18 \mathrm{a}$ \\
Virginia & 2 & $55 \mathrm{~b}$ & $17 \mathrm{~b}$ & $21 \mathrm{~b}$ & $0 \mathrm{~b}$ \\
Virginia & 5 & $3 \mathrm{c}$ & $1 \mathrm{c}$ & $1 \mathrm{c}$ & $0 \mathrm{~b}$ \\
\hline Spanish & 0 & $8 \mathrm{a}$ & $38 \mathrm{a}$ & $39 \mathrm{a}$ & $10 \mathrm{a}$ \\
Spanish & 2 & $4 \mathrm{a}$ & $21 \mathrm{~b}$ & $38 \mathrm{a}$ & $1 \mathrm{a}$ \\
Spanish & 4 & $1 \mathrm{a}$ & $0 \mathrm{c}$ & $0 \mathrm{~b}$ & $0 \mathrm{a}$
\end{tabular}

${ }^{\mathrm{a}}$ Means within a year and market type followed by the same letter are not significantly different at $p \leq 0.05$.

${ }^{\mathrm{b}}$ Spanish market type was dug $14 \mathrm{~d}$ prior to digging both runner and Virginia market types resulting in only 4 sprays for the Spanish market type.

for the Virginia and Spanish market types was higher than defoliation for the runner market type.

Although market type interacted with fungicide regime for defoliation (Tables 2 and 9), this interaction was not significant for pod yield (Table 2). However, the interaction of year $\times$ fungicide regime was significant for pod yield (Table 2). In 3 of 4 experiments (2005, 2006, and 2008), pod yield was higher when fungicides were applied 4 or 5 times compared with the no-fungicide control (Table 10). In 2005 and 2006, yield was lower when only 2 early season sprays were included in the fungicide regime compared with the full-season regime. During 2007 and 2008 yield did not
TABLE 9: Interaction of market type and fungicide spray regime on peanut canopy defoliation at harvest ${ }^{\mathrm{a}}$.

\begin{tabular}{lccc}
\hline Fungicide sprays & \multicolumn{3}{c}{$\begin{array}{c}\text { Fungicide spray program } \\
\text { Canopy defoliation } \\
\text { Virginia } \\
\%\end{array}$} \\
Number & $\begin{array}{c}\text { Sunner } \\
\text { Spanish }\end{array}$ \\
\hline 0 & $8 \mathrm{~b}$ & $24 \mathrm{~b}$ & $33 \mathrm{a}$ \\
2 & $1 \mathrm{c}$ & $1 \mathrm{c}$ & $27 \mathrm{a}$ \\
4 or $5^{\mathrm{b}}$ & $\mathrm{b}$ \\
\hline${ }^{\mathrm{a}}$ Means within a market type followed by the same letter are not significantly \\
different at $p \leq 0.05$. Data are pooled over years and management practices. \\
b Spanish market type was sprayed 4 times with fungicide while the runner \\
and Virginia market types were sprayed 5 times with fungicide. The Spanish \\
market type was dug 14 d prior to digging the runner and Virginia market \\
types.
\end{tabular}

TABLE 10: Peanut yield as influenced by year and fungicide program ${ }^{\mathrm{a}}$.

\begin{tabular}{|c|c|c|c|c|}
\hline \multirow{2}{*}{ Fungicide sprays ${ }^{b}$} & \multicolumn{4}{|c|}{ Peanut yield } \\
\hline & 2005 & 2006 & 2007 & 2008 \\
\hline Number & \multicolumn{4}{|c|}{$\mathrm{kg} / \mathrm{ha}$} \\
\hline 0 & $3,520 \mathrm{~b}$ & $3,750 \mathrm{~b}$ & $3,920 \mathrm{~b}$ & $4,420 \mathrm{~b}$ \\
\hline 2 & $3,900 \mathrm{~b}$ & $4,000 \mathrm{~b}$ & $4,680 \mathrm{a}$ & $4,880 \mathrm{ab}$ \\
\hline 4 or 5 & $4,550 \mathrm{a}$ & $4,810 \mathrm{a}$ & $4,320 \mathrm{ab}$ & $5,050 \mathrm{a}$ \\
\hline
\end{tabular}

${ }^{a}$ Means within a year followed by the same letter are not significantly different at $p \leq 0.05$.

${ }^{\mathrm{b}}$ Spanish market type was sprayed 4 times with fungicide while the runner and Virginia market types were sprayed 5 times with fungicide. The Spanish market type was dug $14 \mathrm{~d}$ prior to digging runner and Virginia market types.

differ when peanut was treated 2 of 4-5 times with fungicide. Carley et al. [44] demonstrated that defoliation of Virginia market types can be variable when 2 early season sprays 
are compared with 5 sprays. They also reported that in most experiments peanut yield was higher with a full-season fungicide regime compared with nontreated peanut.

\section{Conclusions}

A primary objective of this research was to determine if management practice interacted with market types. Runner, Spanish, and Virginia market types did not interact with management practices including application of calcium sulfate to ensure kernel development, inoculation with Bradyrhizobium at planting for biological nitrogen fixation, digging dates, planting patterns, and in experiments comparing control of thrips using aldicarb, southern corn rootworm using chlorpyrifos, eclipta using threshold-based postemergence herbicides, and leaf spot disease with fungicide programs. The only management practice interacting with market type for peanut yield was planting date. These experiments also demonstrated that runner and Virginia market types will yield higher than Spanish market types in many instances. Although the cultivars used in these experiments are not grown on appreciable ha at this time, results can be used to determine management strategies for newer cultivars within these market type designations when developing management strategies.

\section{Competing Interests}

None of the authors has competing interests in terms of products mentioned in the paper.

\section{Acknowledgments}

This research was supported through funds provided by the North Carolina Peanut Growers Association and the Peanut CRSP LAG-00-96-90013-00. Appreciation is expressed to P. D. Johnson, B. Penny, B. Royals, and staff at the Peanut Belt Research Station for technical assistance.

\section{References}

[1] B. Brown, Virginia Type Peanuts: Situation and Outlook, vol. 331 of Peanut Information Publication, 2014.

[2] D. L. Jordan, C. W. Swann, J. F. Spears, R. L. Brandenburg, J. E. Bailey, and M. R. Tucker, "Comparison of virginia and runner market type peanut (Arachis hypogaea L.) grown in the Virginia-Carolina area," Peanut Science, vol. 27, no. 2, pp. 71-77, 2000.

[3] H. T. Stalker and C. E. Simpson, "Germplasm resources in Arachis," in Peanut Science and Technology, pp. 14-53, American Peanut Research and Education Society, 1995.

[4] J. R. Sholar, R. W. Mozingo, and J. P. Beasley Jr., "Peanut cultural practices," in Peanut Science and Technology, pp. 354-382, American Peanut Research and Education Society, Stillwater, Okla, USA, 1995.

[5] M. Balota and P. Phipps, "Comparison of Virginia and runnertype peanut cultivars for development, disease, yield potential, and grade factors in eastern Virginia," Peanut Science, vol. 40, no. 1, pp. 15-23, 2013.
[6] J. W. Chapin and J. S. Thomas, Peanut Varieties, vol. 588 of Peanut Money-Maker Production Guide Circular, 2009.

[7] F. R. Cox and J. R. Sholar, "Site selection, land preparation, and management of soil fertility," in Peanut Health Management, pp. 7-10, The American Phytopathological Society, 1995.

[8] T. P. Gaines, M. B. Parker, and M. E. Walker, "Limestone and gypsum effects on calcium nutrition of 'Florunner' and 'NC-7' Peanuts," Communications in Soil Science and Plant Analysis, vol. 22, no. 1-2, pp. 117-135, 1991.

[9] F. R. Cox, F. Adams, and B. B. Tucker, "Liming, fertilization, and mineral nutrition," in Peanut Science and Technology, pp. 139163, American Peanut Research and Education Society, 1982.

[10] R. J. Henning, A. H. Allison, and L. D. Tripp, "Cultural practices," in Peanut Science and Technology, pp. 123-163, American Peanut Research and Education Society, 1982.

[11] P. D. Johnson, D. L. Jordan, and T. Corbett, "Response of the cultivars CHAMPS and Perry to planting and digging dates in North Carolina," in Proceedings American Peanut Research and Education Society, vol. 45, pp. 39-40, 2013.

[12] D. L. Wright, B. Tillman, J. Marois, J. A. Ferrell, and N. DuFault, "Management and cultural practices for peanuts," Tech. Rep. SS-AGR-74, University of Florida IFAS Extension Publication, 2013, http://edis.ifas.ufl.edu/pdffiles/aa/aa25800.pdf.

[13] T. H. Sanders, A. M. Schubert, and H. E. Pattee, "Maturity methodology and postharvest physiology," in Peanut Science and Technology, H. E. Pattee and C. T. Young, Eds., pp. 624-654, American Peanut Research and Education Society, Yoakum, Tex, USA, 1995.

[14] W. D. Branch, "University of Georgia peanut breeding program," Tech. Rep. CSS-13-0110, University of Georgia Cooperative Extension Service Publication, 2013.

[15] D. L. Ketring, "Physiology of oil seeds. VI. A means to break dormancy of peanut (Arachis hypogaea L.) seeds in the field," Peanut Science, vol. 4, no. 1, pp. 42-45, 1977.

[16] B. Khalfaoui, "Inheritance of seed dormancy in a cross between two Spanish peanut cultivars," Peanut Science, vol. 18, no. 2, pp. 65-67, 1991.

[17] D. S. Carley, D. L. Jordan, R. L. Brandenburg, and L. C. Dharmasri, "Factors influencing response of virginia market type peanut (Arachis hypogaea) to paraquat under weed-free conditions," Peanut Science, vol. 36, no. 2, pp. 180-189, 2009.

[18] P. D. Johnson, D. L. Jordan, R. L. Brandenburg, and B. M. Royals, "Response of peanut to interactions of gypsum and chlorpyrifos," Proceedings American Peanut Research and Education Society, vol. 45, p. 39, 2013.

[19] B. N. Ang, D. A. Herbert, T. P. Mack, and R. L. Hodges, "Relationship of Pod damage by southern corn rootworm and soil drainage to peanut yield," Peanut Science, vol. 21, no. 1, pp. 68-74, 1994.

[20] J. W. Wilcut, A. C. York, W. J. Grichar, and G. R. Wehtje, "The Biology and management of weeds in peanut (Arachis hypogaea)," in Peanut Science and Technology, pp. 207-244, American Peanut Research and Education Society, 1995.

[21] T. G. Isleib, P. W. Rice, R. W. Mozingo, R. W. Mozingo II, and H. E. Pattee, "Registration of 'Gregory' peanut," Crop Science, vol. 39, no. 5, p. 1526, 1999.

[22] W. D. Branch, "Registration of "Georgia Green" Peanut," Crop Science, vol. 36, no. 3, p. 806, 1996.

[23] O. D. Smith, C. E. Simpson, W. J. Grichar, and H. A. Melouk, “Registration of 'Tamspan 90' Peanut," Crop Science, vol. 31, no. 6, p. 1711, 1991. 
[24] T. Baughman, P. Dotray, J. Grichar et al., “Texas peanut production guide," Texas A\&M AgriLife Extension, 2007, http://peanut .tamu.edu.

[25] K. J. Boote, "Growth stages of peanut (Arachis hypogaea L.)," Peanut Science, vol. 9, no. 1, pp. 35-40, 1982.

[26] E. J. Williams and J. S. Drexler, "A non-destructive method for determining peanut pod maturity," Peanut Science, vol. 8, no. 2, pp. 134-141, 1981.

[27] A. C. Bennett, A. J. Price, M. C. Sturgill, G. S. Buol, and G. G. Wilkerson, "HADSS ${ }^{\mathrm{TM}}$, pocket $\mathrm{HERB}^{\mathrm{TM}}$, and WebHADSS ${ }^{\mathrm{TM}}$ : decision aids for field crops," Weed Technology, vol. 17, no. 2, pp. 412-420, 2003.

[28] Z. A. Chiteka, D. W. Gorbet, D. A. Knauft, F. M. Shokes, and T. A. Kucharek, "Components of resistance to late leafspot in peanut. II. Correlations among components and their significance in breeding for resistance," Peanut Science, vol. 15, no. 2, pp. 76-81, 1988.

[29] SAS, GLM Procedure, SAS Institute, 2006.

[30] E. W. Chin Choy, J. F. Stone, R. S. Matlock, and G. N. McCauley, "Plant population and irrigation effects on Spanish peanuts (Arachis hypogaea L.)," Peanut Science, vol. 9, no. 2, pp. 73-76, 1982.

[31] J. P. Damicone, K. E. Jackson, J. R. Sholar, and M. S. Gregory, "Evaluation of a weather-based spray advisory for management of early leaf spot of peanut in Oklahoma," Peanut Science, vol. 21, no. 2, pp. 115-121, 1994.

[32] W. J. Grichar and O. D. Smith, "Variation in yield and resistance to southern stem rot among peanut (Arachis hypogaea L.) lines selected for pythium pod rot resistance," Peanut Science, vol. 19, no. 1, pp. 55-58, 1992.

[33] G. D. Grosz, R. L. Elliott, and J. H. Young, "A comparison of two peanut growth models for Oklahoma," Peanut Science, vol. 15, no. 1, pp. 30-35, 1988.

[34] A. C. Mixon and W. D. Branch, "Agronomic performance of a Spanish and runner cultivar harvested at six different digging intervals," Peanut Science, vol. 12, no. 1, pp. 50-54, 1985.

[35] J. S. Richburg, J. W. Wilcut, and W. J. Grichar, "Response of runner, spanish, and virginia peanut cultivars to imazethapyr," Peanut Science, vol. 33, no. 1, pp. 47-52, 2006.

[36] D. S. Carley, D. L. Jordan, L. C. Dharmasri, T. B. Sutton, R. L. Brandenburg, and M. G. Burton, "Peanut response to planting date and potential of canopy reflectance as an indicator of pod maturation," Agronomy Journal, vol. 100, no. 2, pp. 376-380, 2008.

[37] M. Carroll, T. Britton, C. Fountain, M. Parrish, D. L. Jordan, and P. D. Johnson, "Peanut response to inoculation and ammonium sulfate rate in North Carolina," in Proceedings American Peanut Research and Education Society, vol. 47, p. 55, 2015.

[38] D. L. Jordan, P. D. Johnson, J. F. Spears, B. Penny, and D. Hardy, "Response of Virginia market type peanut to interactions of cultivar, calcium, and potassium," Journal Crop Management, vol. 9, no. 1, 2010.

[39] J. E. Lanier, D. L. Jordan, J. F. Spears et al., "Peanut response to planting pattern, row spacing, and irrigation," Agronomy Journal, vol. 96, no. 4, pp. 1066-1072, 2004.

[40] D. L. Jordan, J. B. Beam, P. D. Johnson, and J. F. Spears, "Peanut response to prohexadione calcium in three seeding rate-row pattern planting systems," Agronomy Journal, vol. 93, no. 1, pp. 232-236, 2001.

[41] W. L. Drake, D. L. Jordan, R. L. Brandenburg, B. R. Lassiter, P. D. Johnson, and B. M. Royals, "Peanut cultivar response to damage from tobacco thrips and paraquat," Agronomy Journal, vol. 101, no. 6, pp. 1388-1393, 2009.

[42] J. W. Chapin and J. S. Thomas, "Effects of chlorpyrifos on pod damage, disease incidence, and yield in two peanut fungicide programs," Peanut Science, vol. 20, no. 2, pp. 102-106, 1993.

[43] W. J. Everman, S. B. Clewis, W. E. Thomas, I. C. Burke, and J. W. Wilcut, "Critical period of weed interference in peanut," Weed Technology, vol. 22, no. 1, pp. 63-67, 2008.

[44] D. S. Carley, D. L. Jordan, B. B. Shew, T. B. Sutton, L. C. Dharmasri, and R. L. Brandenburg, "Influence of digging date and fungicide program on canopy defoliation and pod yield of peanut (Arachis hypogaea L.)," Peanut Science, vol. 36, no. 1, pp. 77-84, 2009. 


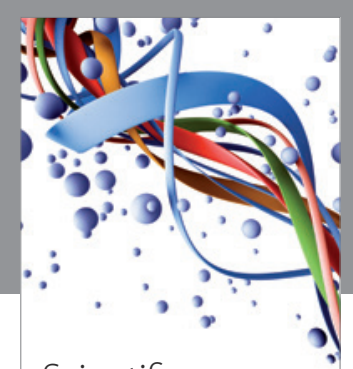

Scientifica
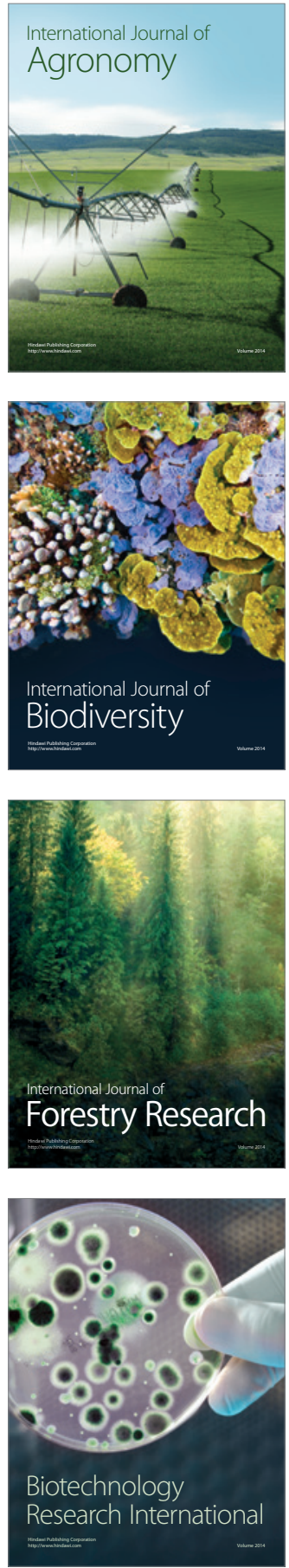
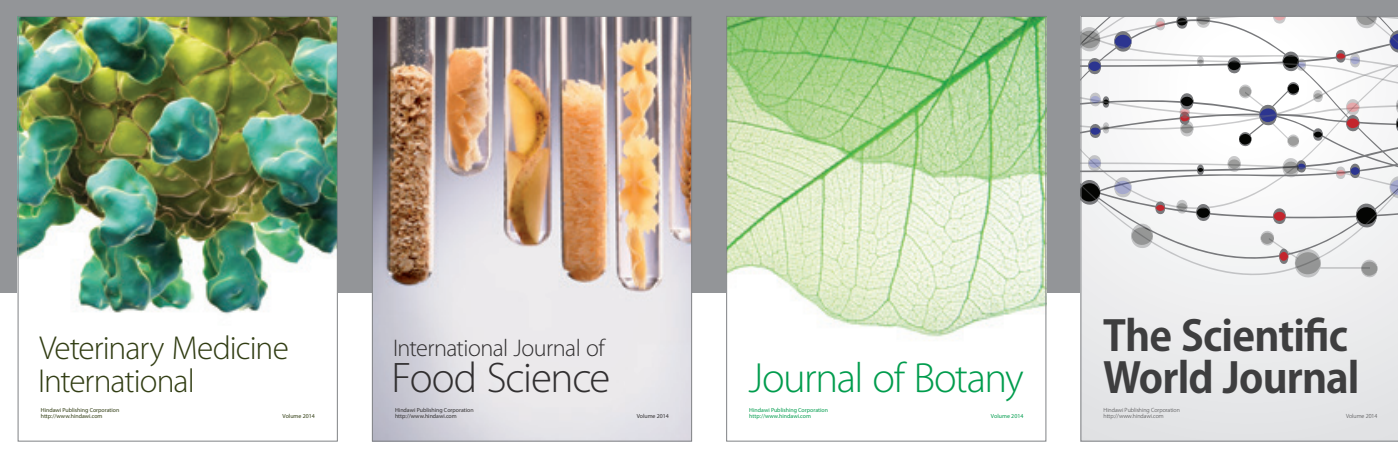

The Scientific

\section{World Journal}

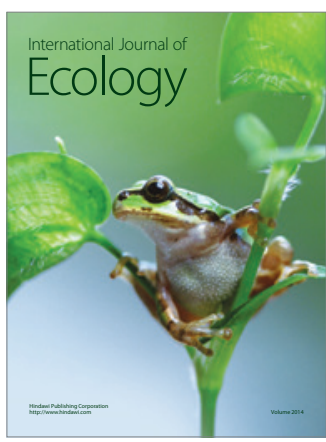

\section{Hindawi}

Submit your manuscripts at

http://www.hindawi.com
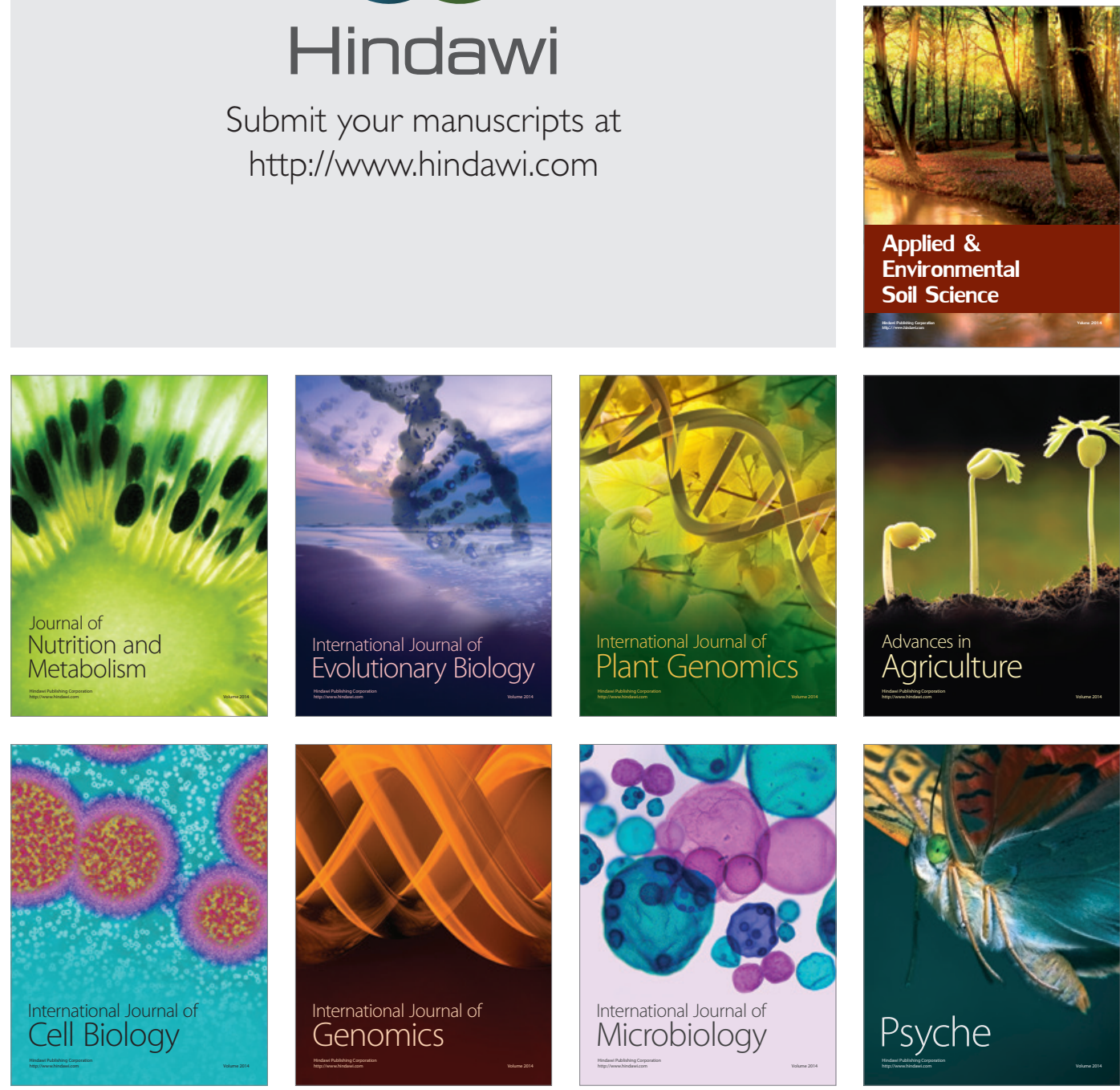
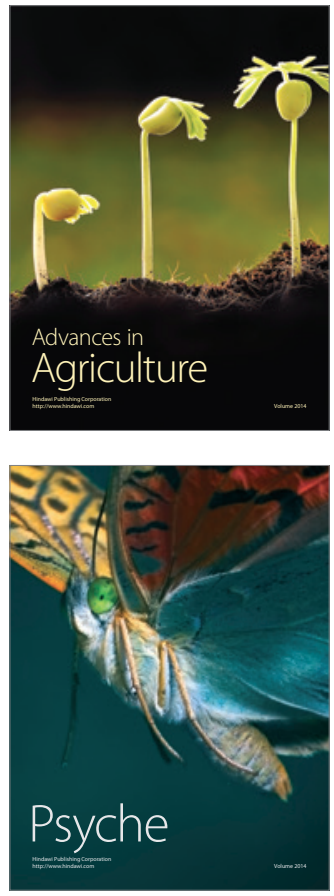